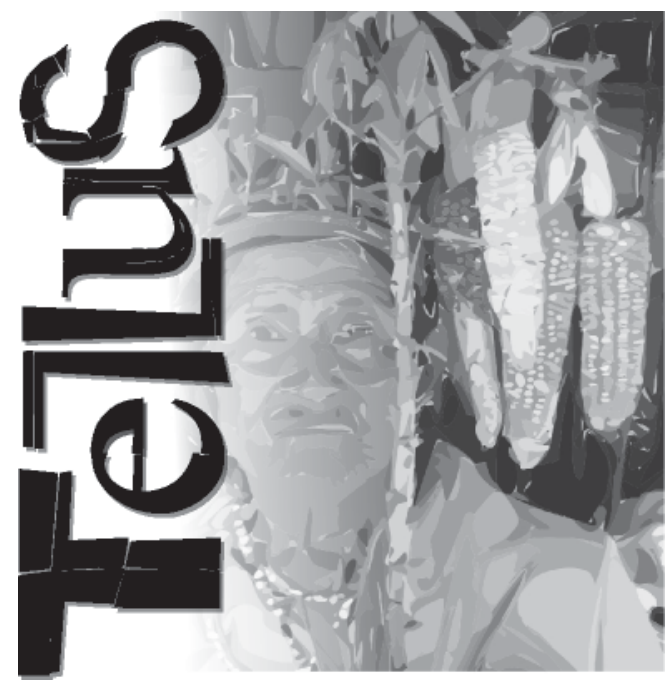

documentos 



\section{O SPI e a exploração de recursos naturais em terras indígenas}

\author{
Lenir Gomes Ximenes* \\ Leandro Skowronski** \\ Daniele Gonçalves Colman***
}

Entre os anos de 1910 e 1967, o órgão responsável pela política indigenista do Estado brasileiro era o Serviço de Proteção aos Índios (SPI). Sua atuação foi marcada pelo paradigma assimilacionista, o que significa que ser indígena era considerado uma condição transitória. Dessa forma, as ações do SPI em relação às terras indígenas estavam atreladas a essa visão. Um dos objetivos do órgão era estimular, entre as diversas etnias, a adoção de hábitos dos não índios (considerados "civilizados") e, de certa forma, a demarcação das Reservas ${ }^{1}$ ia ao encontro desse objetivo. A maioria delas foi demarcada com área muito inferior ao território antes ocupado pelos diversos povos, dificultando assim a manutenção de seus costumes e organização social tradicionais. Nesse contexto, o SPI pretendia inserir os indígenas no sistema econômico nacional, incentivando a produção de bens econômicos nas Reservas, e o emprego de sua mão de obra nos empreendimentos, sobretudo rurais.

Como resultado desse processo, as maneiras de utilização e manejo dos recursos naturais nas áreas indígenas também sofreram alterações. A exploração incentivada, ou pelo menos consentida, pelo SPI contribuiu para colocar em risco a biodi-

\footnotetext{
${ }^{1}$ De acordo com a nomenclatura adotada pela Fundação Nacional do Índio (FUNAI), as Reservas Indígenas são terras doadas por terceiros, adquiridas ou desapropriadas pela União, que se destinam à posse permanente dos povos indígenas. São terras que também pertencem ao patrimônio da União, mas não se confundem com as terras de ocupação tradicional. No entanto, na primeira metade do século XX, as áreas reservadas e demarcadas pelo SPI recebiam a denominação de Reservas. A maioria delas (incluindo a Reserva Indígena Cachoeirinha) são, atualmente, reconhecidas como terras de ocupação tradicional e, por isso, recebem a denominação de Terras Indígenas (logo, Terra Indígena Cachoeirinha). Entretanto, optou-se por manter a expressão Reserva Indígena, por ser a utilizada pelo SPI, órgão indigenista atuante no período a que se referem os documentos mencionados neste texto.
}

* Mestre em História pela Universidade Federal da Grande Dourados (UFGD), docente do curso de História da Universidade Católica Dom Bosco (UCDB), pesquisadora do Núcleo de Estudos e Pesquisas das Populações Indígenas (NEPPI/UCDB). E-mail: lenir_gximenes@hotmail.com

** Mestre em Fitotecnia pela Universidade Federal de Viçosa (UFV), docente do curso de Agronomia da UCDB, pesquisador do NEPPI/UCDB. E-mail: Isk@ucdb.br

*** Acadêmica do curso de História da UCDB, bolsista de extensão do NEPPI/UCDB.

$$
\text { Tellus, ano 14, n. 27, p. 177-183, jul./dez. } 2014
$$

Campo Grande, MS 
versidade de diversas áreas, e o resultado foi o esgotamento de recursos importantes para a manutenção do modo de viver tradicional das diversas etnias.

Diversos documentos atestam essa responsabilidade histórica do Estado brasileiro em relação à situação atual dos povos indígenas, e o objetivo desta publicação é justamente facilitar o acesso dos Terena a esses documentos referentes à sua história, e assim fomentar pesquisas mais aprofundadas sobre a temática.

A documentação da $5^{\mathrm{a}}$ Inspetoria Regional do SPI traz inúmeras referências à exploração de recursos naturais nas áreas dos Terena, no sul do então Mato Grosso, atual estado de Mato Grosso do Sul. Exemplo disso é a Reserva de Cachoeirinha (município de Miranda), demarcada em 1905. Há diversos documentos acerca da extração de madeira e de cascas de tronco de angico na área. De acordo com ofícios e memorandos de funcionários do órgão, em alguns momentos essa extração foi proibida, mas ainda assim acontecia. Em outros momentos o órgão dava o aval, sob a justificativa de angariar recursos para o Posto Indígena. A madeira era vendida para serrarias da região e até mesmo como lenha para a Companhia Ferroviária Noroeste do Brasil (NOB). As cascas de angico eram requisitadas, pois sua resina tem utilização medicinal e industrial.

Salienta-se que eram os próprios Terena que realizavam o trabalho de extração. Ou seja, terra, recursos e força de trabalho indígena eram utilizados durante a gestão do SPI para negociação com terceiros. O engajamento dos Terena nesses trabalhos evidencia por outro lado, suas estratégias de relacionamento com o Estado e com os regionais, em um novo formato de territorialização.

A seguir, a transcrição de alguns desses documentos, que fazem parte do acervo de microfilmes do Fundo/SPI do Museu do Índio, com cópias disponíveis no Centro de Documentação Indígena TekoArandu/NEPPI/UCDB, em Campo Grande, MS, cujo acervo está aberto a pesquisadores de outras instituições e às populações indígenas.

$5-83 / 44-60(75)$

Miranda, 20 de janeiro de 1947

Ao Ilmo. Sr. Cel. Nicolau Bueno Horta Barbosa

Chefe da I.R.5

Campo Grande

a) Assunto: Resposta ao vosso “Contracto de Extração de casca de angico no Posto Indígena de Cachoeirinha"Preços:- Proponho- 
vos pagar pelo arrendamento da mattagem, por arroba (15 kilos) contra conhecimento ferroviario de embarque da E.F. Noroeste, um cruzeiro $(\mathrm{Cr} \$ 1,00)$ ou quarenta mil cruzeiros $(\mathrm{Cr} \$ 40,000,00)$ annuaes, isenta de passagem e da seguinte forma:

1) na assignatura de contratante, quinze mil cruzeiro $(\mathrm{Cr} \$$ $15,000,00)$.

2) decorridos quatro (4) meses da assignatura de contracto...... des mil cruzeiros ( $\mathrm{Cr} \$ 10,000,00)$.,

3) decorridos mais quatro (4) meses os restantes quinze mil cruzeiros $(\mathrm{Cr} \$ 15,000,00)$, perfazendo assim o total de quarenta mil cruzeiros (Cr\$40,000,00).

b) Salarios: de accôrdo

c) Transporte: Será feito das mattas para os depósitos das estradas de rodagem para auto-caminhão mais proximas das estações de embarque, Duque Estrada e Agachy, ficando a conservação da estrada do Posto até a linha divisoria das terras dos indios com o corrego Agachy e deste até a estação de Agachy por minha conta.O material deverá também ser transportado pela estrada de rodagem de Posto que passa pela Fasenda Petropolis à estação de Duque Estrada, afim de facilitar o transporte devido a deficiência do auto-caminhões e combustíveis.

d) Trabalhadores: de accôrdo.-

e) Empregados de Empreiteiro:- de accôrdo.-

f) Lenha: de accôrdo.-

g) Deposito de material: Será feito á margem das estradas de autocaminhões para maior facilidade de empreiteiro e não na séde de Posto, podendo o Agente do mesmo, effectuar a competente fiscalisação semanalmente.

h) Pagamento aos trabalhadores: para commodidade de serviço, e pagamento aos trabalhadores da matta será feito aos sabbados, podendo o mesmo ser effectuado pelo Agente de Posto, feito por feixo como é de praxe e não por arroba devido a difficuldade no fornecimento de vagões para embarque e tambem quanto ao accordo de contas com os trabalhadores.

Saudações

[Assinado] Antonio Ferreira Candido

Rua Candido Mariano 331

Campo Grande

Estado de Mato Grosso 
Fonte: Museu do Índio, Fundo SPI/IR5, Posto Indígena Cachoeirinha, pasta 83, planilha 45, microfilme 76, Miranda, 1947. Cópia no Centro de Documentação Indígena Teko Arandu/NEPPI/UCDB, Campo Grande, 2015.

\section{5-83/45-00 (2-3)}

Sr. Chefe da S.A.

[...] 5- A aquisição de um caminhão para o transporte de lenha de angico é contra-indicada, considerando o alto custo de um veículo destinado somente ao transporte de determinada quantidade de lenha de arvores de angico derrubadas para a extração de casca. Tal serviçojá começou a ser economicamente feito com os veículos do Posto; e a lenha será vendida em Miranda, á proporção que for sendo entregue, á vista. É desaconselhável a venda de lenha á Noroeste, visto que a mesma atraza-se sempre no pagamento, quer de lenha, que de dormentes, ás vezes um ano e mais.

Em 14-8-949

[Assinado] Resp. pelo Exp. Da I.R.5

Fonte: Museu do Índio, Fundo SPI/IR5, Posto Indígena Cachoeirinha, pasta 83, planilha 45, microfilme 3, Campo Grnde, 1949. Cópia no Centro de Documentação Indígena Teko Arandu/NEPPI/UCDB, Campo Grande, 2015.

5-83/45-65 (274)

Exmo.Snr. Miguel P. de Oliveira

M.D. Agente do Posto Indigena da Cachoeirinha em Miranda.

Em 10 de Agosto de 1951

Por meio desta apresento-lhe proposta para arrendamento das matas da Cachoeirinha, dentro das seguintes condições:-

$\left.1^{\circ}\right)$ - Comprometo-me arrendar as matas da Cachoeirinha para extração de casca de angico á razão de Cr.\$1,20 (um cruzeiro e vinte centavos) por arroba de (15) quinze-kilos, sendo que o respectivo pagamento será efetuado por mim no ato de embarque das cascas na Estação da Estrada de Ferro.

$\left.2^{\circ}\right)$ - O serviço de transporte do material será feito em caminhões de minha propriedade- para as Estações de Miranda. Duque Estrada e Agachi, de onde serão despachadas para os Cortumes. $3^{\circ}$ )- Proponho pagar esse preço uma vez que as matas nessa região já estão bastante exploradas, tornando-se assim mais 
difícil o serviço de tiragem do material.

$4^{\circ}$ )- Dou inteira preferência ao pessoal da Aldeia Cachoeirinha para o serviço de tiragem das cascas.

Assim sendo e espero a resolução desse Posto s/mais assunto, sirvo-me do ensejo para apresentar as minhas

Cordiais Saudações

[Assinado] Luiz Pereira Alves

Fonte: Museu do Índio, Fundo SPI/IR5, Posto Indígena Cachoeirinha, pasta 83, planilha 45, microfilme 274, s/1, 1951. Cópia no Centro de Documentação Indígena Teko Arandu/NEPPI/UCDB, Campo Grande, 2015.

5-83/41-63 (106)

Campo Grande, MT

Em 01 de Setembro de 1955

Ao Sr. Encarregado do P.I. Cachoeirinha

Respondendo vosso m/m 63, referente ao indio João Lemos que quer, e deve aproveitar as cascas e madeiras que existem dentro de seu roçado, como seja de Angico, pois estando nessas condições, será justo aproveitar. Todavia, será sempre bom inspecionar para que não sejam devastadas as matas virgens, como já tem acontecido.

Cordialmente

[Assinado] Deocleciano de Souza Nenê

Fonte: Museu do Índio, Fundo SPI/IR5, Posto Indígena Cachoeirinha, pasta 83, planilha 41, microfilme 106, Campo Grande, 1955. Cópia no Centro de Documentação Indígena Teko Arandu/NEPPI/UCDB, Campo Grande, 2015.

$5-83 / 40-65(96)$

Campo Grande, MT

Em 21 de Maio de1957

Ao Sr. Encarregados do P.I. Cachoeirinha

Tendo chegado ao conhecimento desta Chefia a noticia de que alguns indios desse Posto estão pleiteando a tiragem e venda de 
casca de angico, notifico-vos que é terminantemente proibida tal concessão, a quem quer que seja, indios ou civilizados, sob quaisquer pretextos, seja para finalidade fôr, sem que a S.O.A seja ouvida, consultada e opine sobre o assunto, que não será de aprovação, visto que $\mathrm{m} / \mathrm{m}$ circular $\mathrm{n}^{\circ} 159$, da mesma S.O.A, no/

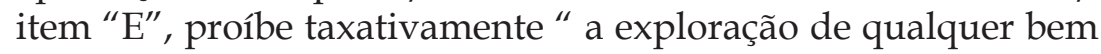
ou riqueza natural", cuja a copia vai anexa ao presente.

Saudações

[Assinado] Erico Sampaio

Chefe da IR 5

Fonte: Museu do Índio, Fundo SPI/IR5, Posto Indígena Cachoeirinha, pasta 83, planilha 40, microfilme 96, Campo Grande, 1957. Cópia no Centro de Documentação Indígena Teko Arandu/NEPPI/UCDB, Campo Grande, 2015.

5-83/40-14 (19)

Campo Grande-MT

Ministério da Agricultura

M/M-No 195/1964

Ao Sr. Encarregado do PI Cachoeirinha

É do conhecimento désta I.R, a existência nêsse PI, de madeiras de cedro já derrubadas em gestões anteriores. Solicitamos da Administração dêsse Pôsto, da possibilidade do aproveitamento de referida madeira néssa Região, dentro do mais curto praso possivel, devendo V.S vir munido das respectivas propostas de interessados, os quais deverão serem discutidas e apreciadas na próxima Reunião a se realizar nésta Séde, no dia 10 de Agôsto vindouro conforme Mem/ cit-18/64 do dia 27 corrente.

Saudações

[Assinado] Alan Cardec Martins Pedroza Chefe IR 5

Fonte: Museu do Índio, Fundo SPI/IR5, Posto Indígena Cachoeirinha, pasta 83, planilha 40, microfilme 19, Campo Grande, 1964. Cópia no Centro de Documentação Indígena Teko Arandu/NEPPI/UCDB, Campo Grande, 2015. 
5-83/40-02 (04)

P.I Cachoeirinha

Em 1 de Agosto de 1964

Ao Sr. Chefe da $5^{a}$ Inspetoria Regional do Serviço de Proteção aos Índios

Campo Grande

Em atenção ao M/M n $^{\circ}$ 195/64 déssa Chefia, venho pelo presente dar a seguinte resposta:

A madeira derrubada, cedros, já examinei pessoalmente e acho dificil de efetuar-se negocio, pois é em média muito fina, são toras de no máximo 40 centímetros de grossura na parte mais grossa, sendo que a serraria em Miranda exige o mínimo de 60 centímetros na ponta mais fina e já tenho procurado obter propostas o que ainda não consegui, apresento este que será melhor explicado quando da minha ida a essa sede.

Saudações

[Assinado] Enc. de Posto

Fonte: Museu do Índio, Fundo SPI/IR5, Posto Indígena Cachoeirinha, pasta 83, planilha 40, microfilme 04, Miranda, 1964. Cópia no Centro de Documentação Indígena Teko Arandu/NEPPI/UCDB, Campo Grande, 2015. 
